\title{
Thermal Performance of Plastic Bottles Walls Reused in Building Construction for Waste Reduction
}

\author{
Mariam Abouhadid, Ashraf Mansour, Rania Shafik, Omar ElRawy
}

Abstract: The research aims at studying the potential of reusing plastic water bottles as a building material and an alternative to traditional bricks, in a way that can minimize waste and hence reduce ecological imbalance.

The research compares the energy performance of building with traditional bricks and building with plastic bottle blocks.

The researchers built digitally two sample rooms: (3 meter width*3 meter length*3 meter Height) with both materials, Then they took on-site measurements for energy performance of the rooms.

The rooms were built on DesignBuilder software in order to help in environmental analysis of buildings, and compare the efficiency of the two materials of sample rooms.

Results showed that building with plastic water bottles has some environmental benefits other than reuse of a material that hardly decomposes. It has its effects on energy saving and thermal comfort. Further research and experiments is encouraged as the plastic residue dilemma grows more in modern societies and affects the ecological balance and wild life.

Keywords : Environmentally friendly, Plastic Bottles, Reuse, Thermal Comfort.

\section{INTRODUCTION}

$\mathrm{W}$ aste is one of the biggest challenges in today's world. Authorities and governments around the world are trying to find solutions for waste reduction and management in order to save the environment from the consequences of waste mismanagement.

Solid Waste in Egypt has been found as $1.2 \mathrm{Kg} / \mathrm{person} /$ day. Rates of waste percentages increase in summer and decrease

Revised Manuscript Received on November 08, 2019.

* Correspondence Author

Mariam Abouhadid* Assistant Professor of Architecture, Civil Department, Engineering Division, at the National Research Center of Egypt, m.abouhadid@gmail.com

Ashraf Mansour Professor of Architecture, Civil Department, Engineering Division, at the National Research Center of Egypt, ashraf_mansour@fulbrightmail.org

Rania Shafik Assistant Professor of Architecture, Civil Department, Engineering Division, at the National Research Center of Egypt, raniashafik@gmail.com

Omar EIRawy Assistant lecturer and research associate at the American University in Cairo (AUC), omaroelrawy@gmail.com in winter and are mostly metal like beverage cans, plastic like water bottles and food products. [1]

Province Daily MSW (Ton)

Annually MSW (Ton)

\begin{tabular}{ccc}
\hline Cairo & 15000 & 5.47 \\
Alexandria & 4000 & 1.46 \\
Giza & 4500 & 1.64 \\
Kaluobya & 3500 & 1.27 \\
Ghrabya & 3500 & 1.27 \\
Behyra & 3500 & 1.27 \\
Sharkia & 1800 & 0.65 \\
Louxer & 250 & 0.09 \\
Aswan & 650 & 0.23 \\
Matroh & 250 & 0.09 \\
Seuz & 400 & 0.14 \\
Red Sea & 450 & 0.16 \\
New Valley & 100 & 0.03
\end{tabular}

Fig. 1: The amount of solid waste in Egypt According to number estimates in 2011, 55 tons of municipal solid waste has been found to be the daily amount in Egypt. It was found that annually, the round estimate reaches 20 million tons of waste in Egypt.

Table I: The daily generated MSW at the different Governorates

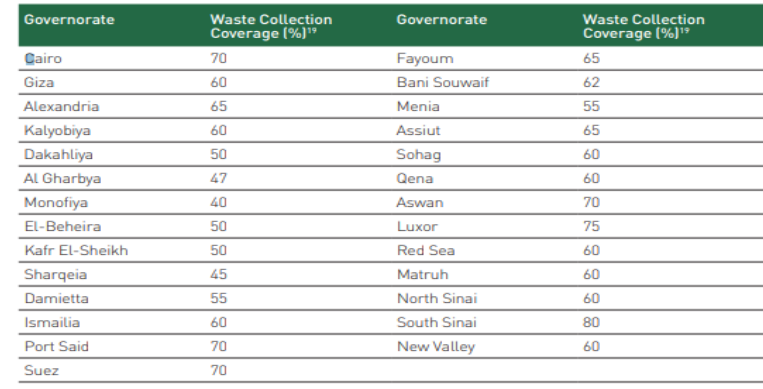

Table 1 shows that the majority of waste comes from Cairo, and the least a waste amounts come from the new valley province, This is a solid indication that population is key when it comes to waste amounts. [2] 


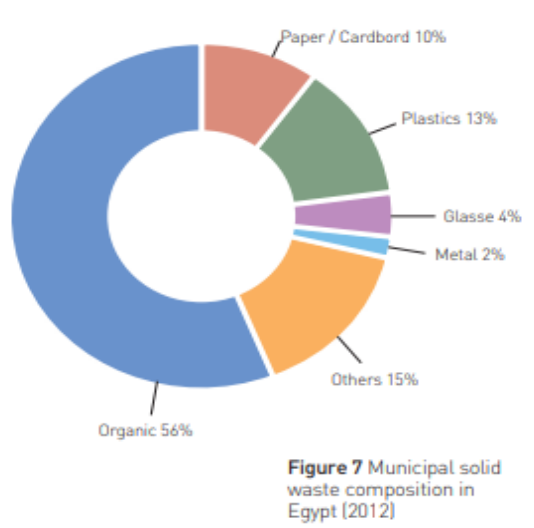

Fig.2: Exhibits the composition of MSW in Egypt in 2012 [3]

Waste composition is affected by different factors such as culture, climate, economic development and energy resources. Waste composition controlled how often waste has to be collected and ways to dispose it. Waste composition in low- income countries mainly constitute of organic waste and food products, while in high-income countries waste is mainly paper, plastics and dry materials. [4]

Plastic Bottles is one of the most found items in the urban waste in modern cities. It has sustainable characterizes due to its nature that promotes it to be reused in long term products such as building construction industry. Research has been made on the possibility of reusing plastic bottles for building and sustainable development. Studies have also mentioned ways for positioning the bottles and stacking them instead of traditional bricks. They also studied how to insulate them thermally and acoustically. They studied the strength points that this material possess in comparison to other traditional materials. It was proven that in many aspects such as flexibility, time of execution, load capacity, cost, waste reduction and energy efficiency, Bricks were more suited than many traditional building materials like bricks, ceramic blocks and concrete.[5] Other researchers have examined the plastic bottles physical characteristics and ways of bonding them; they examined appropriate filler materials like sand and clay. Researchers have also made cost analysis comparing plastic bottles' wall and traditional masonry wall. [6]

A project was done aiming to test the possibility of using waste Plastic bottles as a partial replacement to bricks. The project proved that Plastic bottles represented a more flexible alternative to building blocks, as well as a material that stops crack propagation after initial block formation. The project answered many concerns about the dangers of waste disposals and how to solve this dilemma. [7]

Plastic bottles are perceived as one of the most dangerous waste to the environment due to its decomposable nature. Researches state that the non- renewable materials cannot lead to sustainable development, and may lead to resource depletion and make the coming generations suffer from destructive consequences. It was also proven that Plastic bottles can be used for some construction elements like walls and roofs.

The reuse of plastic bottles in buildings can have substantial results like saving embodied energy. This can be done by reducing the $\mathrm{CO} 2$ emissions due to cement manufacturing; hence the overall energy consumption can be reduced by reducing the percentage of cement used. Plastic bottles wall have been less costly in comparison to bricks and also they provide greater strength.

This approach is considered among one of the most promising materials for green projects in the construction industry.

Regarding Construction cost, Cost compression between bottles wall is half than traditional brick masonry. The reduction of cost using plastic bottles has been stated as being the half of cost of brick walls.

In General the bottle buildings are compliant to users' thermal needs, which mean that when the weather is cold or hot, inside the building temperature is cool. The use of waste materials is a creative way to multiple benefits, this approach can help in energy saving in the construction industry, it can help in light structure and temporary building purposes. The use of Plastic can also help reduce environmental degradation. [8]

An estimated number of 20000 plastic bottles are used to obtain one ton of plastic. It is estimated that each year 100 million tons of plastics are produced. In Europe, an average person discards $36 \mathrm{~kg}$ of plastics in one year. Recycles plastics are used in the production of many things like plastic waste sacks. [9]

According to ENSO [5], plastic bottles manufacturing was negligible in the 1960s. But the rates has been increasing ever since, and the amounts produced are very high in comparison to the amount recycled. (fig.3)

PET Bottles (polyethylene terephthalate) that are not recycles are sent to landfills or as litter. They take around One thousand years to biodegrade. This was the reason behind plastic waste pollution in landfills, oceans, waterways and on the roadsides. This problem continues to grow and is becoming more serious and dangerous to wildlife and the environment.

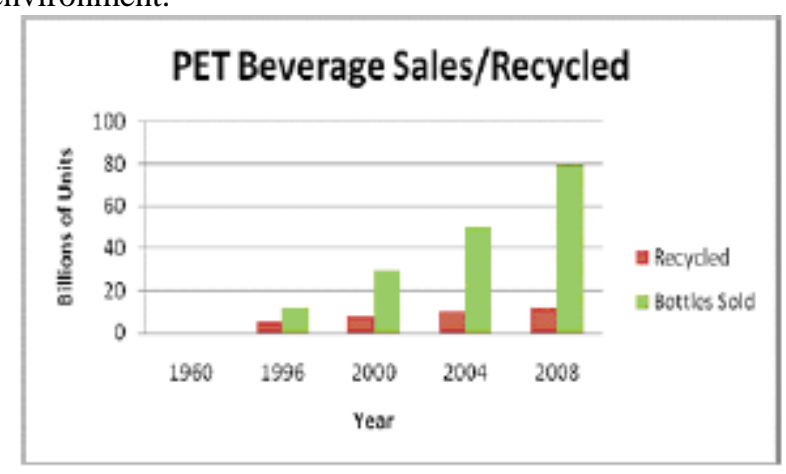

Fig. 3: PET bottles sales/recycled

\section{TOOLS AND METHODS}

\section{A. Methodology}

Literature Review started with a pilot study on similar experiments that were done around the world and what were their findings.

The team built the sample rooms on DesignBuilder software in order to help in environmental analysis of buildings, and compare the efficiency of the two materials of sample rooms. The research followed an experimental approach by simulating the room once with standard wall properties and another simulating the same room with plastic bottles wall assembly; Then comparing both results in terms of thermal comfort, Temperature and relative Humidity. 
The standard reference wall assembly was set based on ASHRAE standard 90.1 energy standard for buildings except low-rise residential buildings. The plastic walls were simulated by calculating the U-value of stacked plastic bottles wall.

Plastic bottles are normally made of Polyethylene Terephthalate PET, Which has thermal conductivity ranging from 0.13 to $0.15 \mathrm{~W} / \mathrm{mK}$.

\section{B. Tools}

Room Details:

$3 m * 3 m * 3 m$ Room Built with Traditional Bricks

$3 m * 3 m * 3 m$ Room Built with Plastic Bottle Block

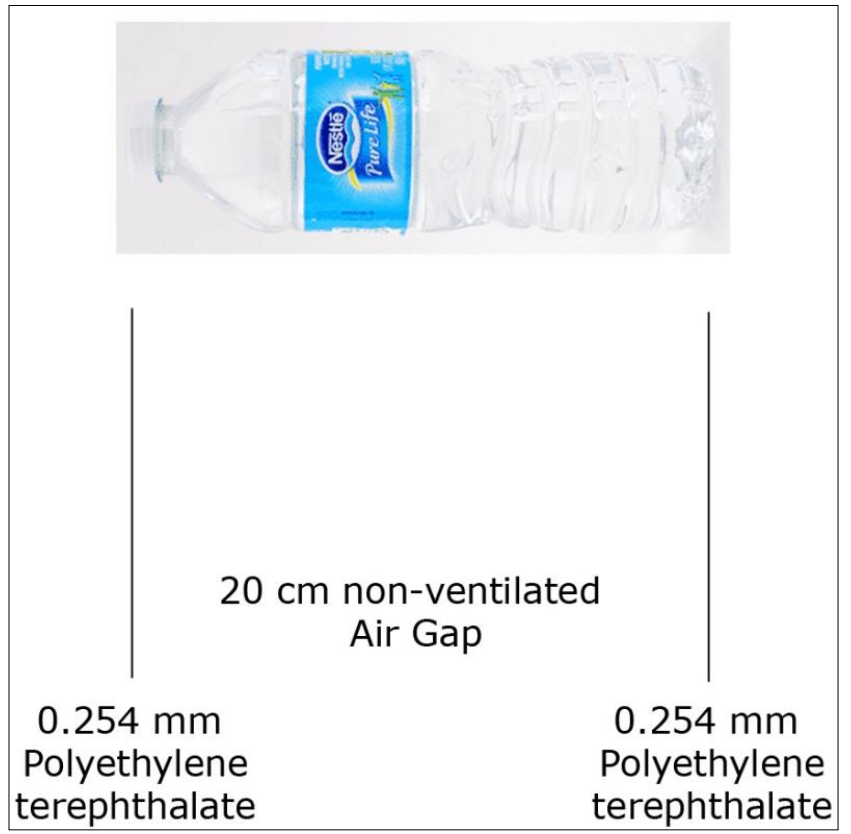

Fig. 4: Bottle's Simulated Assembly. (By the author)

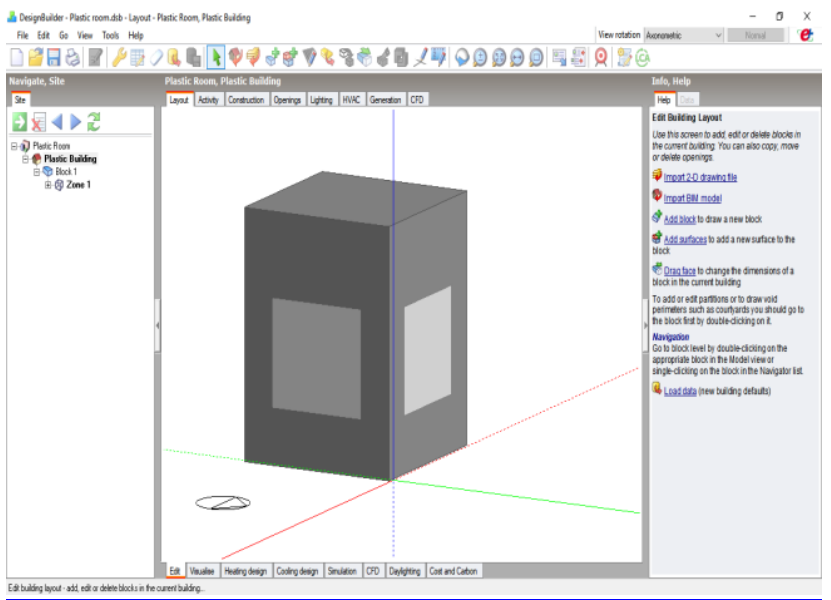

Fig. 5: Simulated Room using DesignBuilder software

\section{TESTS RESULTS}

Figure 6 shows the thermal comfort analysis using standard brick, as per ASHRAE 90.1 standard.

Figure 7 shows the same analysis using the plastic bottles assembly, and Figures 8 \& $9 \& 10$ show both results' comparison, in Temperature, Relative Humidity and Discomfort Hours Comparison.
EnergyPlus Outpu
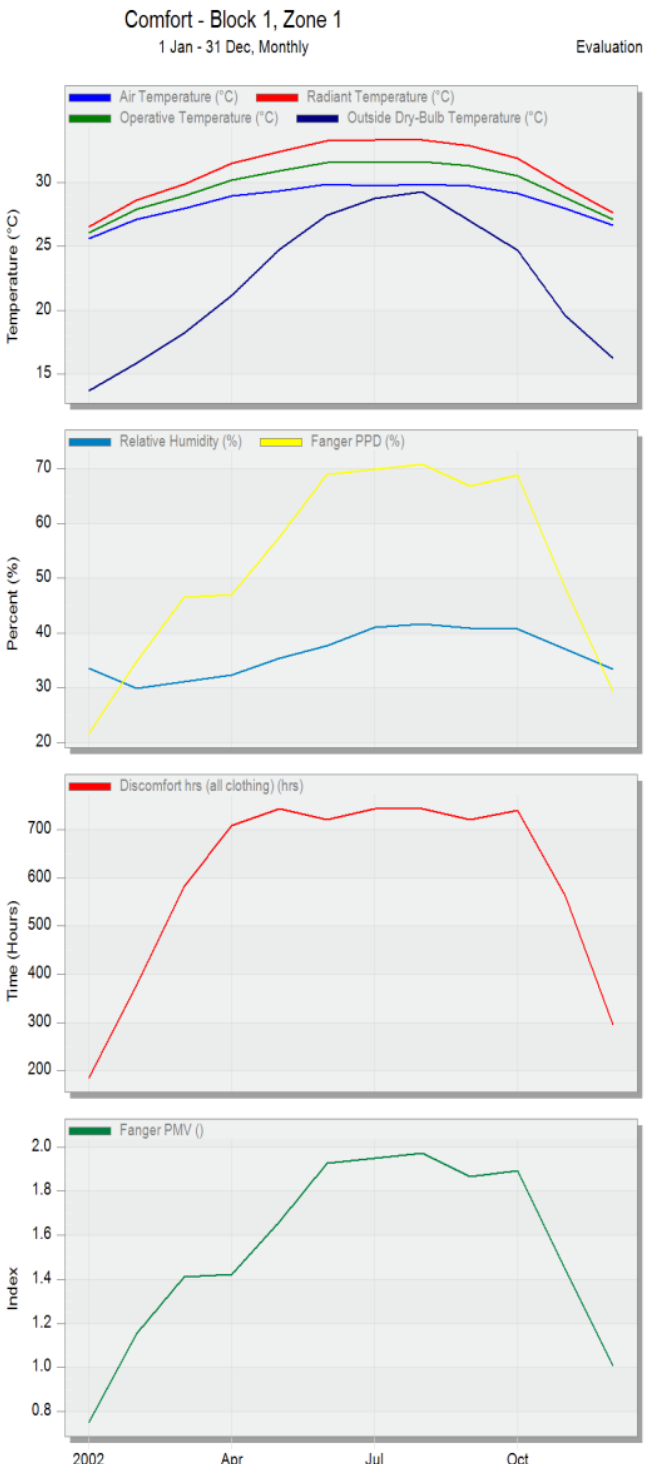

Month 2002

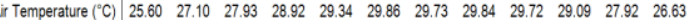
$\begin{array}{llllllllllllll} & \text { Radiant Temperature (C) } & 26.50 & 28.03 & 29.86 & 31.46 & 32.37 & 33.26 & 33.33 & 33.32 & 32.84 & 31.87 & 29.64 & 27.61\end{array}$

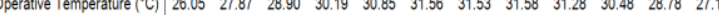

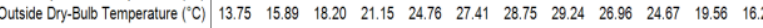

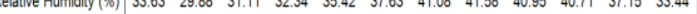
\begin{tabular}{l|lllllllllllllll} 
& Fanger PPD (\%) & 21.63 & 34.85 & 46.46 & 46.96 & 57.52 & 68.90 & 69.80 & 70.80 & 66.76 & 68.74 & 48.21 & 29.50
\end{tabular}

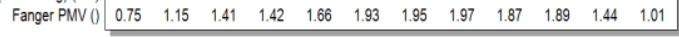

Fig. 6: Results using standard brick walls 
EnergyPlus Output
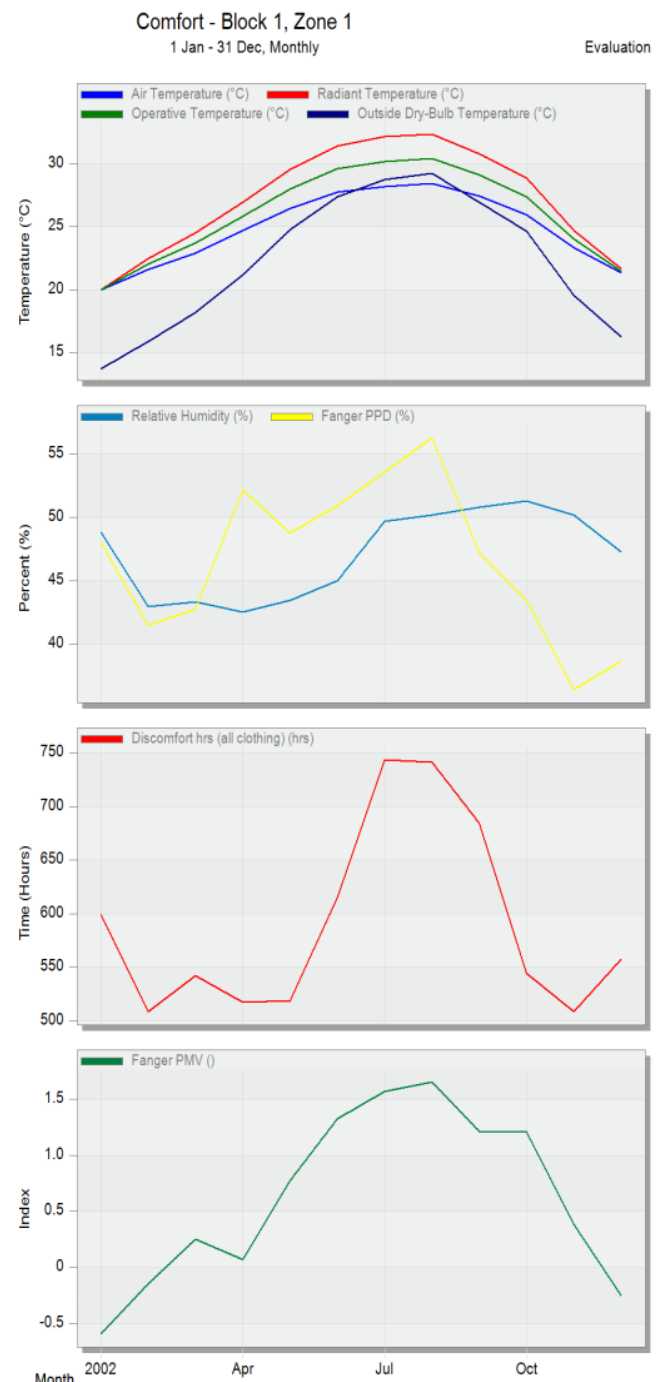

Air Temperature ("C) $20 \begin{array}{lllllllllllll} & 20.00 & 21.63 & 22.94 & 24.72 & 26.45 & 27.77 & 28.21 & 28.46 & 27.46 & 25.94 & 23.35 & 21.34\end{array}$

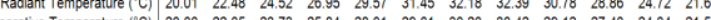
$\begin{array}{lllllllll} & & \end{array}$

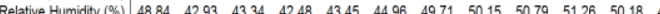

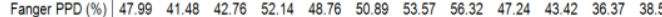
clothing) (hrs) 599505090054250517505190061500744007415068450544505085055800

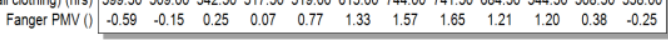

Fig. 7. Results using plastic bottles assembly

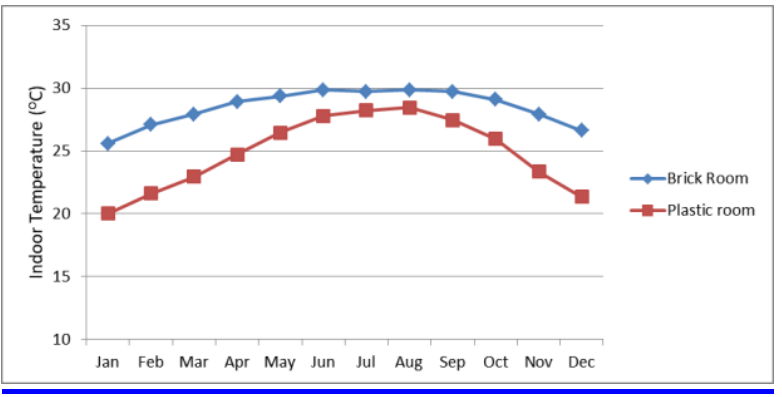

Fig. 8: Indoor Temperature Comparison

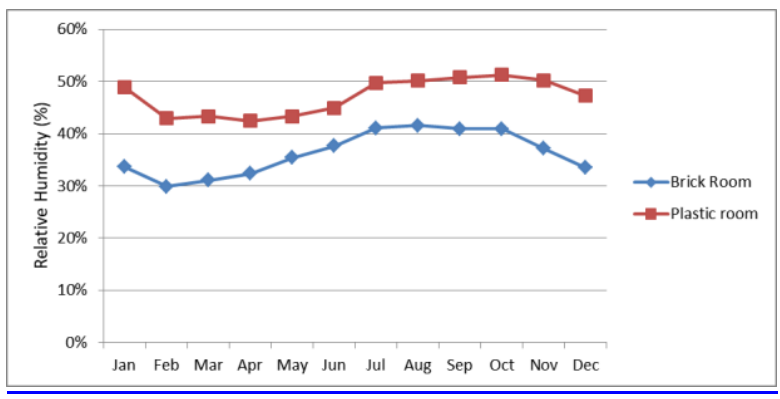

Fig. 9: Indoor Relative Humidity Comparison

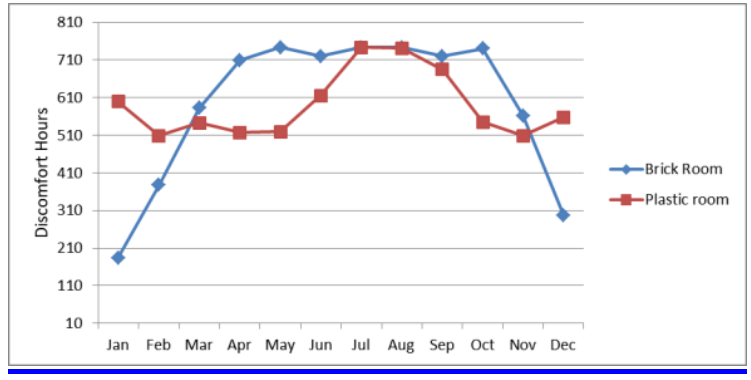

Fig. 10: Discomfort Hours Comparison

Table II: ASHRAE 55 based Thermal Comfort Comparison

\begin{tabular}{|c|c|c|c|}
\hline $\begin{array}{c}\text { Thermal Comfort } \\
\text { Criteria }\end{array}$ & Brick Room & Plastic Room & $\begin{array}{c}\text { \% Reduction in } \\
\text { Discomfort Hours }\end{array}$ \\
\hline $\begin{array}{c}\text { ASHRAE55 80\% } \\
\text { Acceptability Limits } \\
\text { [Discomfort Hours] }\end{array}$ & 6363.5 & 5692.5 & $\mathbf{1 1 \%}$ \\
\hline $\begin{array}{c}\text { ASHRAE55 90\% } \\
\text { Acceptability Limits } \\
\text { [Discomfort Hours] }\end{array}$ & 7727.5 & 6563 & $\mathbf{1 5 \%}$ \\
\hline \hline
\end{tabular}

Thermal comfort is determined in terms of ASHRAE 552010 adaptive thermal comfort model1. (DesignBuilder, n.d.). Both ASHRAE $80 \%$ and $90 \%$ thermal comfort limits are used; The ASHRAE $80 \%$ criterion indicates the annual discomfort hours for all zones in which $80 \%$ of the occupants are expected to report discomfort, while the $90 \%$ criterion indicates the annual discomfort hours for all zones in which $90 \%$ of the occupants are expected to report discomfort. . (ASHRAE, 2010).

\section{RESULT AND DISCUSSION}

The results showed that the average temperature in brick rooms is higher than in the plastic bottles room

However, relative humidity is higher in plastic bottles room; noting that the plastic bottles are empty, not filled with sand for instance, and stacked with no bonding material like cement and mortar.

As for thermal discomfort, the results showed that during months of peak cold (December and January), The Plastic Bottles room had higher discomfort hours average than brick rooms.

${ }^{1}$ adaptive model: a model that relates indoor design temperatures or acceptable temperature ranges to outdoor meteorological or climatological parameters. (ASHRAE, 2010) 
While on months of peak heat (July and August), Plastic room had almost the same average as brick room in discomfort hours.

But the rest of the year, when the temperature in Egypt is relatively stable and neither too hot nor too cold (20-30 degree celsius), results showed that the plastic room had lower rates of discomfort hours average than brick room.

\section{CONCLUSION}

Results of this experiment have shown promising potential of using plastic bottles in light construction in the Egyptian (Cairene) thermal case. It has been proven that it can maintain lower temperature in hot weather, and although relative humidity was higher with plastic, treatments can be considered to be added to plastic to give different results in future research.

\section{REFERENCES}

1. The data collection method involved sorting and weighing the wastes from one house consecutively for seven days, observations, and interview with the chief of waste collection and environmental services in the company for the reconstruction and tourism development. " Municipal Waste Management in Egypt: An Investigation Study of Collection and Generation Process in Alexandria City, Egypt".

2. El Gazzar R. et al., "Municipal Waste Management in Egypt: An Investigation Study of Collection and Generation Process in Alexandria City, Egypt", International Journal of Scientific and Engineering Research 5(6):3, July 2014.

3. Hoornweg D. et al., What a Waste - A Global Review of Solid Waste Management", Urban Development Series, Knowledge Papers, No. 15 , The World Bank, March 2012.

4. New center for Integrated studies of Land \& Environment (NILE) "Annual Report for solid waste management in Egypt", Ministry of State for Environmental Affairs, 2013.

5. Shoubi M., "Investigating the Application of Plastic Bottle as a Sustainable Material in the Building Construction", January 2013

6. Rawat A. et al., "PET Bottles as Sustainable Building Material: A Step Towards Green Building Construction", August 2014.

7. Sajane A. et al., "Construction of houses using plastic bottles", International Journal of Engineering Technology Science and Research, ISSN 2394 - 3386, Volume 4, Issue 4, April 2017.

8. Patela P. et al., "Waste plastic bottles offering innovative building materials with sustainable application", International Journal of Innovative and Emerging Research in Engineering, Volume 3, Issue 3, 2016.

9. ASHRAE. (2010). ASHRAE Standard 55-2010 - Thermal Environmental Conditions for Human Occupancy. 1791 Tullie Circle NE, Atlanta, GA 30329.

10. DesignBuilder. (n.d.). Output Options. Retrieved June 11, 2019,from https://designbuilder.co.uk/helpv4.7/Content/Output_Options.htm

11. Polyethylene terephthalate - Material information. (n.d.). Retrieved May 15, 2019, from http://www.goodfellow.com/E/Polyethylene-terephthalate.html

12. The Berkey. (n.d.). What numbers of plastic are safe for water bottles. The Numbers Behind Water Bottles. Retrieved from https://theberkey.com/blogs/water-filter/what-numbers-of-plastic-forwater-bottles-are-safe-for-you-the-numbers-behind-plastic-bottles.

\section{AUTHORS PROFILE}

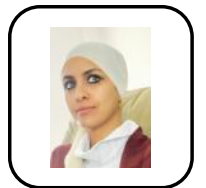

Mariam Abouhadid Assistant Professor of Architecture, Civil Department, Engineering Division, at the National Research Center of Egypt. With 15+ years of experience in Architectural Design, Computer Aided Design, Heritage Conservation and Academia.

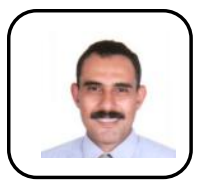

Ashraf Mansour Professor of Architecture, Civil Department, Engineering Division, at the National Research Center of Egypt, With 30+ years of experience in Environmental Design, Research and Academia.

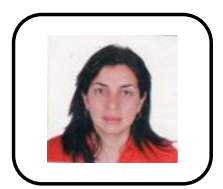

Rania Shafik Assistant Professor of Architecture, Civil Department, Engineering Division, at the National Research Center of Egypt With 15+ Years of experience in Architectural Design, Urban Planning and Academia.

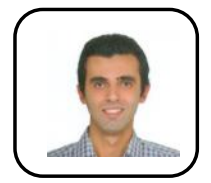

Omar EIRawy Assistant lecturer and research associate at the American University in Cairo (AUC), With 5+ years of experience in green buildings' practice as well as research and academia. 